\title{
Acetic acid buffer as extraction medium for free and bound phenolics from dried blackcurrant (Ribes nigrum L.) skins
}

Article

Accepted Version

Azman, E. M., Charalampopoulos, D. and Chatzifragkou, A. (2020) Acetic acid buffer as extraction medium for free and bound phenolics from dried blackcurrant (Ribes nigrum L.) skins. Journal of Food Science, 85 (11). pp. 3745-3755. ISSN 0022-1147 doi: https://doi.org/10.1111/1750-3841.15466 Available at https://centaur.reading.ac.uk/92602/

It is advisable to refer to the publisher's version if you intend to cite from the work. See Guidance on citing.

To link to this article DOI: http://dx.doi.org/10.1111/1750-3841.15466

Publisher: Wiley

All outputs in CentAUR are protected by Intellectual Property Rights law, including copyright law. Copyright and IPR is retained by the creators or other copyright holders. Terms and conditions for use of this material are defined in the End User Agreement.

www.reading.ac.uk/centaur 
Central Archive at the University of Reading

Reading's research outputs online 


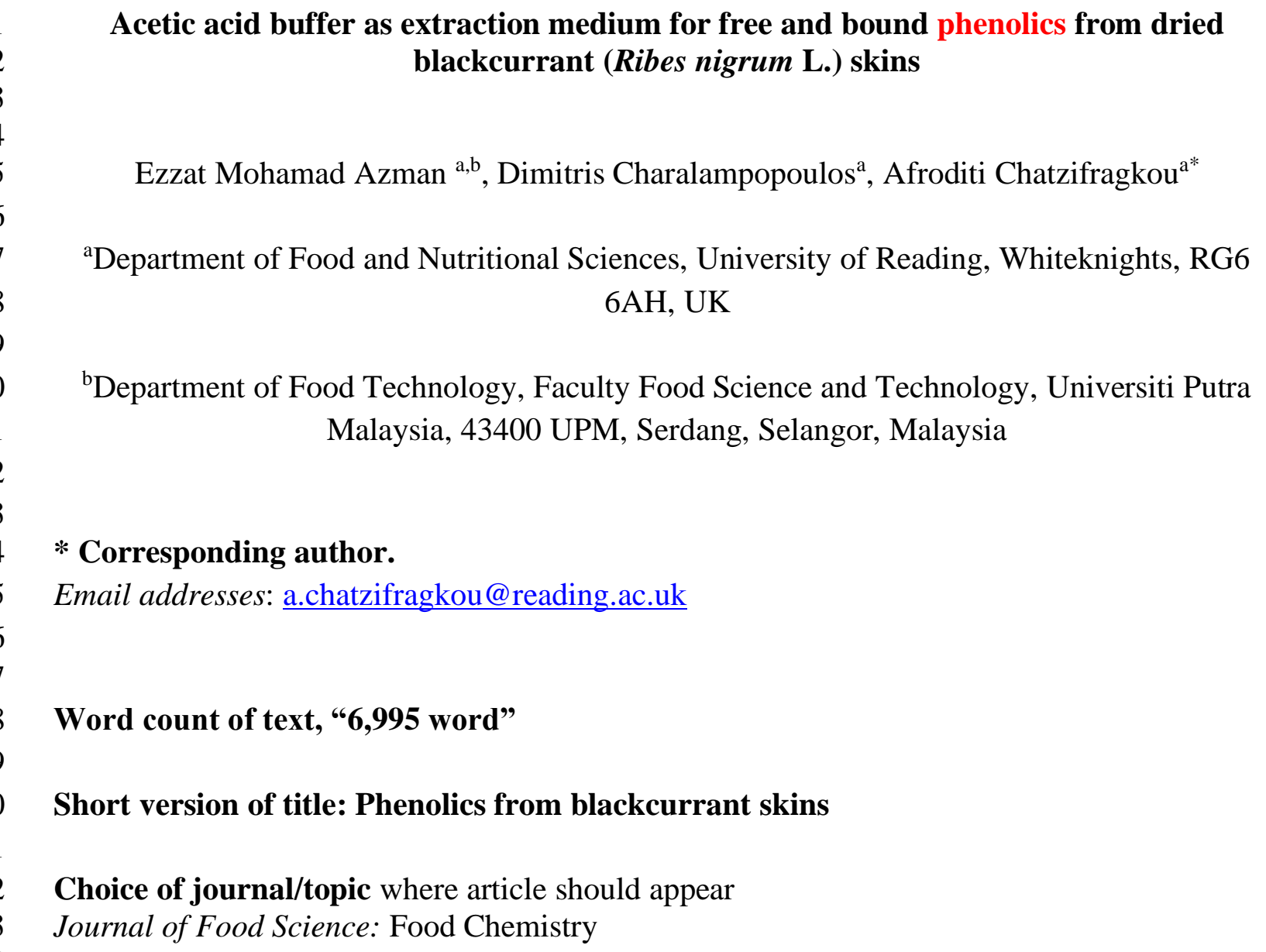
blackcurrant (Ribes nigrum L.) skins 
The aim of this study was to investigate the effects of different solvent and extraction temperatures on the free and bound phenolic compounds and antioxidant activity of dried blackcurrant skins (DBS). Apart from acetic acid buffer solution, different solvent systems including water, methanol, and mixtures of methanol/water were also employed and the effects of solvent and temperature $\left(30^{\circ} \mathrm{C}\right.$ and $\left.50{ }^{\circ} \mathrm{C}\right)$ on the free and bound forms of anthocyanins,

31 hydroxycinnamic acids and flavonols yield were assessed. The results showed that amongst all 32 solvents, acetic acid buffer resulted in the highest free anthocyanin content $(1712.3 \pm 56.1$ $\mathrm{mg} / 100 \mathrm{~g})(p<0.05)$ after $2 \mathrm{~h}$ extraction at $50{ }^{\circ} \mathrm{C}$ from DBS, while lower amounts of bound anthocyanins and anthocyanidins were detected after acid hydrolysis. Acetic acid buffer extracts exhibited the highest free hydroxycinnamic acid content $(268.0 \pm 4.5 \mathrm{mg} / 100 \mathrm{~g})$, total phenolic content $(3702.2 \pm 259.3 \mathrm{mg}$ GAE$/ 100 \mathrm{~g})$ and DPPH activity $(60.7 \pm 2.0 \%$ of inhibition $)$. However, their free flavonol content was slightly lower $(60.2 \pm 0.8 \mathrm{mg} / 100 \mathrm{~g})$ compared to $100 \%$ methanol at $30{ }^{\circ} \mathrm{C}$ and $50{ }^{\circ} \mathrm{C}, 71.4 \pm 1.5 \mathrm{mg} / 100 \mathrm{~g}$ and $71.5 \pm 6.2 \mathrm{mg} / 100 \mathrm{~g}$, respectively. Two-way ANOVA indicated interactions between solvent and temperatures $(p<0.05)$, which suggested that the relationship between solvent and phenolic compounds depends on the extraction temperature.

Practical Application: Overall, acetic acid buffer is more environmentally friendly, efficient and cost-effective than other solvents, thus offering an improved extraction method for phytochemicals as valuable ingredients for nutraceutical applications, from under-utilised dried blackcurrant skins (DBS). 
Keywords: dried blackcurrant skins, anthocyanins, HPLC, antioxidant activity, acetic acid buffer

Blackcurrant (Ribes nigrum L.) is recognised as an economically important soft fruit crop in Europe, Russia, Northern Asia, New Zealand and North America (Battino et al., 2009). Nowadays there are approximately 50 growers that occupy 2,400 hectares in the British Isles and produce around 11,000 tonnes of blackcurrant per year (IBA, 2018). Blackcurrants are generally cultivated for food applications, as it can be used as natural colourants due to their

high content of anthocyanins and proanthocyanins, as preservatives and as sources of ascorbic acid ( 180 mg/100 g of berries) and phenolic compounds (500 - $1342 \mathrm{mg} / 100 \mathrm{~g}$ of berries); the latter have been associated with health promoting effects in humans (Brennan \& Graham, 2009; Basegmez et al., 2017). Anthocyanins, flavonoids, hydroxycinnamic acids, $p$-coumaric acid,

61 myricetin, quercetin, kaempferol glycosides and isorhamnetin shape the phenolic compounds 62 profile of the blackcurrant fruit (Sójka \& Król, 2009), that can be associated primarily with their 63 high antioxidant activities (Szajdek \& Borowska, 2008). Blackcurrants are processed to produce 64 a range of functional ingredients, such as blackcurrant-pomace dietary fibers and defatted seeds, 65 which can be incorporated into jams, jellies, purées and teas (Varming, Peterson, \& Poll, 2004). In the UK, $75 \%$ of the total fresh blackcurrant production is processed into juice (Vagiri, 2014) with $15 \%$ is by-products (Pap et al., 2005) that equals to 1,650 tonnes per year. By68 products of the blackcurrant juice process (skins, seeds and stems) are collected during the 69 pressing stage. Only a small percentage of these by-products is recycled or upgraded, and the 70 majority is used as animal feed (although there are limitations in this regard due to their high 71 acidity and rancid taste) and composting material or is disposed through alternative routes (e.g. 
land spreading) (Arvanitoyannis, 2010). Taking into account the fact that most phenolic

73 compounds are accumulated in the skin of fruits (Mäkilä et al., 2016), an additional value chain

74 can be created through the extraction of phenolic compounds from these by-products.

Extraction is the most important step in the isolation of phenolic compounds including

anthocyanins; however, there is no standardised method for their extraction. The initial step to extract phenolic compounds from plant materials such as berries include grinding, drying and soaking of the samples in extraction solvents such as water, organic solvents and acids (Anderson \& Markham, 2005). Dried plant materials are normally used as starting materials for anthocyanin extraction in order to minimise the possibility of anthocyanin degradation due to chemical reactions taking place in the wet material (Harbourne, Marete, Jacquier, \& O'Riordan, 2013).

Due to the polarity of anthocyanins, polar solvents such as aqueous mixtures of methanol, ethanol or acetone are often employed for their extraction (Kähkönen, Hopia, \& Heinonen, 2001). Also, since water can extract more polar compounds, and ethanol or methanol can extract more hydrophobic compounds, the ratio of the water and methanol or ethanol mixture can be adjusted according to the polarity and solubility of anthocyanins (Lapornik, Prošek, \& Wondra, 2005). Moreover, acidified methanol with hydrochloric or formic acid has been commonly used as an extractant in order to disrupt the cell membrane as well as dissolve the water-soluble anthocyanins (Rodriguez-Saona \& Wrolstad, 2001; Amr \& Al-Tamimi, 2007).

Phenolics compounds that can be extracted by aqueous organic solvents from plant materials are known as extractable phenolics or free phenolic compounds. Free phenolics are mainly deposited in the plant vacuoles and have relatively low molecular weight such as extractable proanthocyanidins, hydrolysable tannins, hydroxycinnamic acids and flavonoids 
96 (Saura-Calixto, 2012; Durazzo, 2018). Anthocyanins and flavonols are examples of flavonoids

97 (Zhang \& Tsao, 2016). In contrast, the non-extractable or bound phenolics are insoluble in

98 aqueous organic solvents, thus remain in the solid residues after extraction. They are bound to

99 protein or cell wall polysaccharides and can only be released by acid, alkaline or enzymatic

100 hydrolysis treatments. Examples of bound phenolics are high molecular weight of

101 proanthocyanidins and hydrolysable tannins, phenolic acids such as ferulic acid, caffeic acid

102 and sinapic acid (Saura-Calixto, 2012; Acosta-Estrada, Gutiérrez-Uribe, \& Serna-Saldívar,

103 2014; Durazzo, 2018; Gulsunoglu, Karbancioglu-Guler, Raes, \& Kilic-Akyilmaz, 2019).

104 Until today, many studies have reported free phenolics extraction from juice, marc and 105 pressed residues of blackcurrant by-products but very few from dried blackcurrant skins, 106 especially focusing on both free and bound phenolic compounds. Therefore, this study aimed to 107 evaluate the effects of different solvents and extraction temperatures on the free and bound 108 phenolic compounds content and the antioxidant activity of blackcurrant using HPLC analysis 109 and DPPH assay. In addition, the correlation between free anthocyanins, free phenolics, 110 antioxidant activity and colour intensity, as well as the interaction between solvent and 111 extraction temperature on the extraction yield of phenolic compounds will be evaluated.

112

113 2. MATERIALS AND METHODS

$114 \quad 2.1$ Chemicals

115 All solvents and chemicals used for extraction, including methanol (99.9\%), ethanol 116 (99.8\%), formic acid (95\%) and acetic acid (99.7\%), were of analytical grade and were 117 purchased from Sigma-Aldrich (UK). Folin-Ciocalteu reagent, sodium carbonate, potassium 118 chloride, sodium acetate, 1, 1-diphenyl-2-picrylhydrazyl (DPPH) were also purchased from 
119 Sigma-Aldrich (UK). Hydrochloric acid (37\%) was purchased from Fisher Scientific

120 (Loughborough, UK).

121 A stock solution of $2 \mathrm{mM}$ DPPH was prepared in methanol. Buffer solutions of

$122 \mathrm{pH} 1.0$ (potassium chloride, $0.025 \mathrm{M}$ ) and $\mathrm{pH} 4.5$ (sodium acetate, $0.4 \mathrm{M}$ ) were prepared as 123 described by Lee, Durst, \& Wrolstad (2005). Purified water was used in all preparations, 124 obtained by a Purite reverse osmosis system (Oxon, UK). Anthocyanin standards of cyanidin125 3-O-glucoside (96\%), cyanidin-3-O-rutinoside (96\%), delphinidin-3-O-glucoside (95\%), and 126 delphinidin-3-O-rutinoside (95\%), cyanidin (96\%), delphinidin (96\%), kaempferol-3-O127 glucoside (99\%), kaempferol-3-O-rutinoside (98\%), quercetin-3-O-rutinoside (99\%) and 128 myricetin-3-O-glucoside (99\%) were obtained from ExtraSynthese Ltd (Genay, France). In

129 addition, quercetin (95\%), myricetin (98\%), kaempferol (99\%), caffeic acid (98\%), p-coumaric 130 (98\%), ferulic acid (99\%) and quercetin-3-O-glucoside (98\%) were purchased from Sigma131 Aldrich (UK).

132

$133 \quad 2.2$ Sample preparation of plant materials

134 Dried blackcurrant pressed residues derived from a juice manufacturing process were 135 kindly supplied by Purn House Farm, (Bleadon, Weston-super-Mare, UK). Dried blackcurrants 136 were separated from the seeds by grinding in a coffee blender and passed through a $0.841 \mathrm{~mm}$ 137 (20 mesh) sieve; this constituted the dried blackcurrant skins (DBS) sample. Samples were 138 segregated in polyethylene bags and stored at $-20{ }^{\circ} \mathrm{C}$ until further analysis.

\subsection{Preparation of dried blackcurrant skins (DBS) extracts}


143 [100\% methanol, 100\% water, and mixtures of methanol-water (50\%, and 70\%, v/v)] in a

144 shaking water bath $(200 \mathrm{rpm})$ at $30{ }^{\circ} \mathrm{C}, 50{ }^{\circ} \mathrm{C}, 70{ }^{\circ} \mathrm{C}$ and $90{ }^{\circ} \mathrm{C}$. The durations of the extraction

145 were set at $0.5,1,2,4$ and $6 \mathrm{~h}$. Moreover, extractions using acetic acid buffer solutions at an

146 acidic $\mathrm{pH}$ value of 1.5 were also carried out in order to investigate the influence of solvent,

147 temperature and solvent-temperature interaction on anthocyanins and phenolics extraction.

148 Duran bottles were tightly closed using polybutylene terephthalate (PBT) caps with

149 polytetrafluoroethylene (PTFE) faced silicone cap liner in order to prevent the evaporation of

150 solvents during the extraction process. The obtained extracts were filtered using a vacuum filter

151 to remove the solid residues.

152

$153 \quad 2.4$ Determination of total monomeric anthocyanin content

154 In preliminary studies, total monomeric anthocyanin content of DBS was determined by

155 the differential $\mathrm{pH}$ method based on the property of anthocyanins to change colour at different

$156 \mathrm{pH}$ values (Lee et al., 2005). As such, $600 \mu \mathrm{L}$ of anthocyanins extracts were mixed with $1.2 \mathrm{~mL}$

157 of corresponding buffer $(\mathrm{pH} 1.0$ and $\mathrm{pH} 4.5)$ and allowed to equilibrate for $20 \mathrm{~min}$. The total

158 monomeric anthocyanin (mg cyanidin-3-O-glucoside equivalents/g dry weight) was calculated

159 as follows:

160

$$
\mathrm{C}_{\text {anthocyanin }}=\frac{A \times M W \times D F \times 10^{3}}{\varepsilon \times 1} \quad \text { Eq. } 1
$$

161 where $\mathrm{C}_{\text {anthocyanin }}=$ otal monomeric anthocyanin concentration (cyanidin-3-O-glucoside

162 equivalents, mg/L); $\mathrm{A}($ absorbance $)=\left(\mathrm{A}_{520 \mathrm{~nm}}-\mathrm{A}_{700 \mathrm{~nm}}\right) \mathrm{pH} 1.0-\left(\mathrm{A}_{520 \mathrm{~nm}}-\mathrm{A}_{700 \mathrm{~nm}}\right) \mathrm{pH} 4.5 ; \mathrm{MW}$

163 (molecular weight $)=449.2 \mathrm{~g} / \mathrm{mol}$ for cyanidin-3-O-glucoside; DF = dilution factor; $1=$

164 pathlength in $\mathrm{cm} ; \varepsilon=26900$ molar extinction coefficient in $\mathrm{L} / \mathrm{mol} / \mathrm{cm}$ for cyanidin-3-O-

165 glucoside; and $10^{3}$ = factor for conversion from $\mathrm{g}$ to $\mathrm{mg}$ (Lee et al., 2005). The anthocyanin

166 content was then calculated by Eq. 2 as follows: 


$$
\text { Anthocyanin content }\left(\frac{m g}{g} \text { of dry weight }\right)=\frac{\text { C anthocyanin }\left(\frac{m g}{L}\right) \times \operatorname{extract}(L)}{\operatorname{sample}(g)} \text { Eq. } 2
$$

The absorbance of the samples at $520 \mathrm{~nm}$ and $700 \mathrm{~nm}$ was determined using a spectrophotometer (Thermo Electron Corporation, USA).

170

\subsection{HPLC analysis of phenolic compounds}

172 Free phenolics. HPLC analysis of free phenolics was based on a method by Kapasakalidis,

173 Rastall, \& Gordon (2006) with slight modifications. HPLC analysis was performed in a 1200

174 Infinity HPLC system (Infinity 1200 series, Agilent Technologies, UK) equipped with a diode-

175 array detector (DAD) using a Zorbax C18 column $(250 \times 4.6 \mathrm{~mm}$ i.d., particle size $5 \mu \mathrm{m}$,

176 Agilent, UK) at $30{ }^{\circ} \mathrm{C}$. The mobile phase consisted of $5 \%$ formic acid (v/v) (solvent A) and

$177100 \%(\mathrm{v} / \mathrm{v})$ methanol (solvent B). The gradient elution protocol was: $15 \%$ (B) at $0 \mathrm{~min}$,

178 increasing to $35 \%$ (B) at $15 \mathrm{~min}$ and to $60 \%$ (B) at $30 \mathrm{~min}$, and reaching $80 \%$ (B) at $40 \mathrm{~min}$

179 before decreasing back to $15 \%$ at $45 \mathrm{~min}$. The flow rate was $1.0 \mathrm{~mL} / \mathrm{min}$ and the injection

180 volume was $20 \mu \mathrm{L}$. The duration of the analysis was $50 \mathrm{~min}$.

181 Free phenolic compounds were quantified in three subclasses: free anthocyanins

182 (consisting of cyanidin-3-O-glucoside, cyanidin-3-O-rutinoside, delphinidin-3-O-glucoside,

183 and delphinidin-3-O-rutinoside; detected at $520 \mathrm{~nm}$ ), hydroxycinnamic acids (consisting of

184 caffeic acid, $p$-coumaric acid and ferulic acid; detected at $320 \mathrm{~nm}$ ) and flavonols (consisting of

185 myricetin-3-O-glucoside, quercetin-3-O-glucoside, quercetin-3-O-rutinoside, myricetin, 186 kaempferol-3-O-glucoside, kaempferol-3-O-rutinoside, quercetin and kaempferol; detected at $187360 \mathrm{~nm}$ ). Briefly, $2.0 \mathrm{mg} / \mathrm{mL}$ of stock standard solutions were prepared separately followed by 188 dilution to give concentrations from 0.01 to $1.0 \mathrm{mg} / \mathrm{mL}$ (anthocyanins), 0.05 to $1.0 \mathrm{mg} / \mathrm{mL}$ 189 (hydroxycinnamic acids) and 0.001 to $0.05 \mathrm{mg} / \mathrm{mL}$ (flavonols). To obtain the standard curves, 
the peak areas were plotted against the corresponding concentrations of the standard solutions

191 injected into HPLC.

192

193 Bound phenolics. For the determination of bound phenolics, a method described by Hertog,

194 Hollman, \& Venema (1992) was used. After free phenolics extraction, the remaining residues

195 were hydrolysed to release the cell wall-bound phenolics. A $7 \mathrm{~mL}$ volume of acidified (with

196 hydrochloric acid 2 M) 60\% (v/v) aqueous methanol was added to each residue and placed in

197 an oven at $90{ }^{\circ} \mathrm{C}$ for $90 \mathrm{~min}$. Samples were allowed to cool down, and supernatants were filtered

198 through a $0.22 \mu \mathrm{m}$ syringe filter. Stock standard solutions $(2.0 \mathrm{mg} / \mathrm{mL})$ of anthocyanidins

199 (cyanidin and delphinidin) were prepared separately and were diluted to give working solutions

200 with concentrations ranging from 0.01 to $1.0 \mathrm{mg} / \mathrm{mL}$. Calibration curves were obtained by

201 plotting the peak areas against the corresponding concentrations of the standard solutions 202 injected into the HPLC.

203

204

205

206 (Waterman \& Mole, 1994) with slight modifications. $20 \mu \mathrm{L}$ of 4-fold diluted extracts were

207 added to $1.58 \mathrm{~mL}$ of distilled water and $100 \mu \mathrm{L}$ of Folin-Ciocalteu reagent. After $8 \mathrm{~min}, 300$

$208 \mu \mathrm{L}$ of sodium carbonate $(75 \mathrm{~g} / \mathrm{L})$ were added. The absorbance of the samples was measured at

$209765 \mathrm{~nm}$ after $2 \mathrm{~h}$ of incubation at room temperature against a blank sample (water instead of

210 extract). Gallic acid $(0-100 \mathrm{mg} / \mathrm{L})$ was used as standard for the calibration curve. The results

211 were expressed as milligrams of gallic acid equivalents per $100 \mathrm{~g}$ of dried weight (mg GAE/100

212 g DW). Duplicate measurements were taken and mean values were calculated. 


\subsection{Determination of total antioxidant activity}

The free radical scavenging activity of DBS extracts on the stable DPPH radical was carried out according to the procedure described by Blois (1958) with slight modifications. $200 \mu \mathrm{L}$ of 50-fold diluted extracts were mixed with $2 \mathrm{~mL}$ of $2 \mathrm{mM}$ methanolic solution of DPPH.

218 The absorbance was measured at $517 \mathrm{~nm}$ after keeping the samples at $30{ }^{\circ} \mathrm{C}$ in the dark, for 30 min. The percentage of inhibition was calculated using the following equation:

$$
\text { Inhibition }(\%)=\frac{A_{\mathrm{o}}-A_{\mathrm{e}}}{A_{\mathrm{o}}} \times 100 \quad \text { Eq.3 }
$$

$\mathrm{A}_{\mathrm{o}}=$ Absorbance of the control; $\mathrm{Ae}=$ Absorbance of the sample

\subsection{Colour measurement}

The colour of the extracts was determined using a Hunter-Lab colourimeter (Hunter Lab,

226 ColourQuest, Hunter Associates Laboratory, Virginia, USA) based on three colour coordinates, $($ Lightness/darkness $; 0-100), a^{*}($ positive $=$ redness/negative $=$ greenness $)$ and $b^{*}($ positive $=$

230 yellowness/negative $=$ blueness $)$. The total colour difference $(\Delta \mathrm{E})$ between two samples was

231 calculated according to the following formula:

232

$$
\text { Total colour difference }(\Delta E)=\left[\left(L^{*}-L_{\mathrm{o}}\right)^{2}+\left(a^{*}-a_{\mathrm{o}}\right)^{2}+\left(b^{*}-b_{\mathrm{o}}\right)^{2}\right]^{1 / 2}
$$

234 where, $L_{o}, a_{0}, b_{o}=$ blank values of control samples extracted at $30 \mathrm{~min}$, according to free 235 anthocyanins content 
238 qualitative attribute of colours which are defined as reddish, greenish, yellowish and bluish. The

239 chroma and hue angle can be calculated using the $a^{*}$ and $b^{*}$ values according to the equations

240 below (Wrolstad and Smith, 2010).

241

242

243

244

245

$$
\operatorname{Chroma}(c)=\sqrt{\left(a^{*}\right)^{2}+\left(b^{*}\right)^{2}} \quad \text { Eq. } 5
$$

$$
\text { Hue angle }(h)=\operatorname{ArcTan}\left(\frac{b^{*}}{a^{*}}\right) \quad \text { Eq. } 6
$$

\subsection{Statistical analysis}

All statistical analyses were conducted by one-way and two-way analysis of variance (ANOVA). Tukey's multiple range tests were employed with a probability of $p<0.05$. The linear Pearson correlation was also used to evaluate correlations between free anthocyanin, total free phenolics, antioxidant activity, chroma and $a^{*}$ values. The software for statistical analysis was Minitab V.16 (Minitab Inc., State College, Pennsylvania, USA).

\section{RESULTS AND DISCUSSION}

Based on the results of total monomeric anthocyanin content during preliminary studies

(Supplementary Table 1) and due to the thermal sensitivity of free anthocyanins, extractions at $30{ }^{\circ} \mathrm{C}$ and $50{ }^{\circ} \mathrm{C}$ for $2 \mathrm{~h}$ were chosen as the best conditions, whereas no significant difference was observed in the extraction of total monomeric anthocyanins within the first $2 \mathrm{~h}$ in the case of all solvent and acid extractions. Consequently, these extracts were then subjected to HPLC analysis to identify the types of anthocyanins, flavonols and hydroxycinnamic acids present. 
261 were detected at $520 \mathrm{~nm}$ (Figure 1). In addition, Figure 2 and Figure 3 show the HPLC 262 chromatograms of free and bound hydroxycinnamic acids and flavonols detected at 320 and 360

$263 \mathrm{~nm}$, respectively. Notably, anthocyanins can also be detected at 320 and $360 \mathrm{~nm}$, but at lower 264 amounts.

\subsection{Free and bound anthocyanins}

Generally, among the four free anthocyanins in all DBS, delphinidin-3-O-rutinoside was the predominant $(p<0.05)$ free anthocyanin (delphinidin-3-O-rutinoside; $~ 50.4 \%>$ cyanidin269 3-O-rutinoside; $\sim 29.1 \%>$ delphinidin-3-O-glucoside; $\sim 20.7 \%>$ cyanidin-3-O-glucoside; $270 \sim 8.6 \%$ ) (Figure 1a). This trend was similar to the work reported by Borges, Degeneve, Mullen, 271 \& Crozier (2009) with blackcurrant fruit extracted with methanol/formic acid (99:1, v/v) using 272 a homogeniser for $1 \mathrm{~min}$.

According to Padayachee et al. (2013), bound anthocyanins and phenolic acids bonded 274 to the cell wall cellulose and pectin through hydrogen bonding and/or hydrophobic interactions.

275 In this study, bound anthocyanins were detected as delphinidin-3-O-glucoside and cyanidin-3-

276 O-glucoside based on the comparison of the retention time as shown in Figure 1b. Interestingly, 277 not only bound anthocyanins, but also proanthocyanidins and anthocyanins in the DBS residue 278 were also hydrolysed to form anthocyanidins, namely delphinidin and cyanidin. Similar results 279 were observed in the study by Kapasakalidis et al. (2006), whereas acid hydrolysis of solvent 280 extracted blackcurrant pomace residue produced approximately $200-700 \mathrm{mg} / 100 \mathrm{~g}$ of total 281 bound anthocyanins and anthocyanidins (delphinidin and cyanidin). 
anthocyanin and phenolic extraction (Table 1). As expected, significantly higher $(p<0.05)$ free anthocyanins $(1712.3 \pm 56.1 \mathrm{mg} / 100 \mathrm{~g})$ was obtained compared to $30{ }^{\circ} \mathrm{C}(1397.5 \pm 21.5 \mathrm{mg} / 100$ $\mathrm{g})$. This is higher than that reported by Lapornik et al. (2005), whereas $1360.0 \pm 10.0 \mathrm{mg} / 100 \mathrm{~g}$ of free anthocyanins was extracted when using $70 \%$ methanol for $24 \mathrm{~h}$ at room temperature.

Not only at $50{ }^{\circ} \mathrm{C}$, extraction using acetic acid buffer at $30{ }^{\circ} \mathrm{C}$ also shows higher concentrations of total free anthocyanins than in water $(292.7 \mathrm{mg} / 100 \mathrm{~g}-551.7 \mathrm{mg} / 100 \mathrm{~g})$, methanol $(1109.4 \mathrm{mg} / 100 \mathrm{~g}-1164.8 \mathrm{mg} / 100 \mathrm{~g})$ and methanol/water $(1135.7 \mathrm{mg} / 100 \mathrm{~g}-1301.2$ $\mathrm{mg} / 100 \mathrm{~g}$ ) extractions (Table 1). The $\mathrm{pH}$ value of the $100 \%$ methanol solution was 4.3 to 4.7;

292 the $\mathrm{pH}$ ranged between $\sim 3.6$ and $\sim 3.8$ in the $50 \%$ methanol extractions and increased slightly to $2933.9-4.1$ when higher concentrations of methanol/water (70\%) were applied. It is apparent that 294 the application of extremely low $\mathrm{pH}(\mathrm{pH}$ 1.5) enabled the efficient extraction of high amounts 295 of free anthocyanins. Acids are considered suitable extractants to extract phenolic compounds 296 as they may facilitate the disruption of the cell membrane and act as a dissolving medium of 297 water- soluble pigments as suggested by Amr and Al- Tamimi (2007).

As shown in Table 1, extraction using water at $50{ }^{\circ} \mathrm{C}$ showed significantly higher $(p<$ 299 0.05) free anthocyanins $(551.7 \pm 0.5 \mathrm{mg} / 100 \mathrm{~g})$ compared to $30^{\circ} \mathrm{C}$. Both water extracts showed 300 up to 3.0 times $(p<0.05)$ higher of anthocyanidins and bound anthocyanins than free 301 anthocyanins. Lower free anthocyanins but higher anthocyanidins content indicated that acid 302 hydrolysis helped to hydrolyse the remaining anthocyanins and proanthocyanidins in the DBS 303 residues. This is due to the fact that water was ineffective in extracting free anthocyanins due to 304 low diffusion rates and solubility of analytes compared to other solvents as suggested by 305 Oancea, Stoia, \& Coman (2012). However, there is no interaction between solvent and 306 temperature on the yield of anthocyanidins. 
Moreover, $100 \%$ methanol extractions at $30{ }^{\circ} \mathrm{C}$ showed relatively higher free and bound

308 anthocyanins and anthocyanidins $(1164.8 \pm 5.9 \mathrm{mg} / 100 \mathrm{~g}, 53.4 \pm 5.2 \mathrm{mg} / 100 \mathrm{~g}$ and $814.1 \pm 18.9$

$309 \mathrm{mg} / 100 \mathrm{~g}$ ), as compared to counterpart at $50{ }^{\circ} \mathrm{C}$. With regards to the absolute water or methanol

310 extractions used at $50^{\circ} \mathrm{C}$, significantly higher $(p<0.05)$ free anthocyanins were observed in the

311 methanol than in the water extracts. This suggests that methanol is a better extractant for free

312 anthocyanins compared to water. Boeing et al. (2014) also reported that methanol was the most

313 efficient solvent compared to ethanol, acetone and water in extractions carried out with black

314 mulberry, blackberry and strawberry.

315 In the extractions using $70 \%$ and $50 \%$ methanol, $50{ }^{\circ} \mathrm{C}$ exhibited a higher extraction 316 yield of free anthocyanins, equal to $1301.2 \pm 5.3 \mathrm{mg} / 100 \mathrm{~g}$ and $1242.5 \pm 1.5 \mathrm{mg} / 100 \mathrm{~g}$,

317 respectively, compared to $30^{\circ} \mathrm{C}$. On the other hand, regarding the effect of the concentrations 318 of methanol/water used, $70 \%$ mixture showed relatively higher free anthocyanins than $50 \%$ 319 methanol at both low and high extraction temperatures.

320 Overall, in methanol extractions, $70 \%$ methanol resulted in relatively higher free 321 anthocyanins content than $100 \%$ and $50 \%$ methanol, whereas there was an increase in the yield 322 of free anthocyanins when water content of methanol/water solution was decreased. 323 Kapasakalidis et al. (2006) suggested that this difference occurred because anthocyanins are 324 polar and are more efficiently extracted in water-containing solvents. Moreover, according to 325 the mass transfer principles discussed by Spigno, Tramelli, \& De Faveri (2007), higher solvent 326 to water ratios have an important role towards the efficiency of extraction.

327 As shown in Table 1, amongst all extraction conditions, the percent yield of delphinidin328 3-O-glucoside and cyanidin-3-O-glucoside were highest in the acetic acid buffer $\mathrm{pH} 1.5$ extracts $329\left(30^{\circ} \mathrm{C}\right)$. Meanwhile, delphinidin-3-O-rutinoside and cyanidin-3-O-rutinoside were highest in 330 water at $30{ }^{\circ} \mathrm{C}$ of extraction. These suggested that extraction at $30{ }^{\circ} \mathrm{C}$ was capable to extract 
331 higher amount of some free anthocyanins compared to $50{ }^{\circ} \mathrm{C}$. Approximately $73.9 \%$ of free 332 anthocyanins were recovered in acetic acid extraction, while $1.4 \%$ and $33.5 \%$ of bound 333 anthocyanins and anthocyanidins, respectively were released by acid hydrolysis of DBS residue.

334 The yield of bound anthocyanins was in agreement with previous studies, reporting $1.0 \%$ of 335 total bound anthocyanins from black carrot puree (Padayachee et al., 2013).

336 Furthermore, except water, all DBS extracts had significantly $(p<0.05)$ higher ratio of

337 free anthocyanins to total anthocyanidins and bound anthocyanins, which differed from 1.4 338 (100\% methanol at $30{ }^{\circ} \mathrm{C}$ ) to 2.8 (acetic acid buffer $\mathrm{pH} 1.5$ at $50{ }^{\circ} \mathrm{C}$ ). Even though delphinidin339 3-O-rutinoside and cyanidin-3-O-rutinoside were two major free anthocyanins found in all 340 extracts, none of them was detected as bound anthocyanins (Table 2). Cyanidin-3-O-glucoside 341 was the lowest free anthocyanin found in the extracts, however, appeared as the most dominant 342 bound anthocyanin in all residues $(83.8 \%$ - 100\%). Other than that, delphinidin-3-O-glucoside 343 was also observed as bound anthocyanins, but only in DBS residues after water and $100 \%$ 344 methanol extractions at low concentrations $(9.3 \%-16.2 \%)$.

348 3. According to the results, $p$-coumaric acid ( 61.6\%) was the main free hydroxycinnamic acid 349 in all DBS extracts, followed by caffeic $(\sim 35.6 \%)$ and ferulic acid $(\sim 18.5 \%)$. Not only free 350 anthocyanins, acetic acid buffer was also efficient in the free hydroxycinnamic acid extraction 351 whereas higher $(p<0.05)$ concentrations were recorded at $50{ }^{\circ} \mathrm{C}(268.0 \pm 4.5 \mathrm{mg} / 100 \mathrm{~g})$ than $35230{ }^{\circ} \mathrm{C}(206.0 \pm 2.3 \mathrm{mg} / 100 \mathrm{~g})$. At $50{ }^{\circ} \mathrm{C}$, total free hydroxycinnamic acid was also significantly 353 higher $(p<0.05)$ compared to water and 50\% methanol. 
355 was detected at $50{ }^{\circ} \mathrm{C}$ extract $(140.4 \pm 0.2 \mathrm{mg} / 100 \mathrm{~g})$ compared to $30{ }^{\circ} \mathrm{C}(78.8 \pm 2.4 \mathrm{mg} / 100 \mathrm{~g})$.

356 However, in $100 \%$ methanol extractions, $30{ }^{\circ} \mathrm{C}$ showed relatively higher total free 357 hydroxycinnamic acids $(276.3 \pm 9.0 \mathrm{mg} / 100 \mathrm{~g})$ compared to $50{ }^{\circ} \mathrm{C}(264.4 \pm 2.4 \mathrm{mg} / 100 \mathrm{~g})$. 358 Moreover, in the extractions using mixtures of methanol/water, $70 \%$ methanol $\left(50{ }^{\circ} \mathrm{C}\right.$ and 30 $\left.359{ }^{\circ} \mathrm{C}\right)$ extracts showed significantly higher total free hydroxycinnamic acid concentrations $(\sim 254.4$ $360 \mathrm{mg} / 100 \mathrm{~g})$ than $50 \%$ methanol $(\sim 228.7 \mathrm{mg} / 100 \mathrm{~g})$.

361 The percent yield of caffeic acid was significantly higher $(p<0.05)$ in water $\left(30{ }^{\circ} \mathrm{C}\right)$, $362100 \%$ methanol $\left(50^{\circ} \mathrm{C}\right)$ and acetic acid buffer $\mathrm{pH} 1.5\left(50{ }^{\circ} \mathrm{C}\right)$ extracts, whilst $p$-coumaric acid 363 was high in water and $100 \%$ methanol extracts at $50{ }^{\circ} \mathrm{C}$. Also, ferulic acid showed a higher 364 percentage of yields in $50 \%$ methanol at $30{ }^{\circ} \mathrm{C}$ and $50{ }^{\circ} \mathrm{C}$ extractions. Overall, the application 365 of acetic acid buffer and $70 \%$ methanol at $50{ }^{\circ} \mathrm{C}$, and $100 \%$ methanol at both temperatures 366 extracted higher total free hydroxycinnamic acids compared to other solvents used.

367 According to Table 3, p-coumaric acid was the only bound hydroxycinnamic acid 368 detected in all DBS residues. Amongst all DBS residues, significantly $(p<0.05)$ higher $p$ 369 coumaric acid was extracted in DBS residues after water ( 47.8 mg/100 g) and 100\% methanol $370(\sim 47.0 \mathrm{mg} / 100 \mathrm{~g})$ extractions compared to acetic acid buffer $\mathrm{pH} 1.5(\sim 42.9 \mathrm{mg} / 100 \mathrm{~g})$. 371 Moreover, DBS residue from 100\% methanol extraction also exhibited higher yield of free and 372 bound hydroxycinnamic acids compared to other residues. This might indicate that the polarity 373 of methanol is suitable to extract both free and bound hydroxycinnamic acids. This finding was 374 in agreement with the study by Haminiuk et al. (2014), where absolute methanol was shown as 375 the most effective solvent for the extraction of phenolic acids and flavonols from Eugenia 376 pyriformis fruit. Gulsunoglu et al. (2019) also reported small amounts of $p$-coumaric acid (0.8 $377 \pm 0.1 \mathrm{mg} / 100 \mathrm{~g})$ as bound hydroxycinnamic acid in black carrot pomace. However, it is 
noteworthy to mention that acid hydrolysis at high temperature might also denature

379 hydroxycinnamic acids in the residue.

380

\subsection{Free and hydrolysed flavonols}

Flavonols are a subgroup of flavonoids and can typically be found in the vacuole of fruits and vegetables. Myricetin, quercetin, kaempferol and fisetin are among the most studied flavonols (Panche, Diwan, \& Chandra, 2016). As shown in Table 4, myricetin-3-O-glucoside was the main free flavonol $(p<0.05)$ detected in both $50{ }^{\circ} \mathrm{C}$ and $30{ }^{\circ} \mathrm{C}$ water extracts $(\sim 28.6 \%$ to $\sim 29.0 \%$ ), followed by quercetin-3-O-glucoside; no kaempferol was detected. There was no significant difference $(p>0.05)$ in the total free flavonol content between these two extraction temperatures. Laaksonen et al. (2014) reported similar trends for free flavonols obtained in blackcurrant juices produced by pressing blackcurrants at an industrial scale.

According to the free flavonol contents in the acid extracts as shown in the Table 4, the application of higher extraction temperature $\left(50{ }^{\circ} \mathrm{C}\right)$ resulted in significantly $(p<0.05)$ higher total free flavonols $(60.2 \pm 0.8 \mathrm{mg} / 100 \mathrm{~g})$ than $30{ }^{\circ} \mathrm{C}(47.4 \pm 0.5 \mathrm{mg} / 100 \mathrm{~g})$. On the other hand, extraction using $100 \%$ methanol at both temperatures led to significantly $(p<0.05)$ higher total free flavonol concentrations compared to other solvents including acetic acid buffer. In addition, quercetin-3-O-glucoside appeared to be the major free flavonol in the acid extracts $(26.4 \%-$ $27.6 \%)$, followed by myricetin-3-O-glucoside ( $21.1 \%$ to $\sim 21.9 \%)$.

Moreover, there is no significance difference in the free flavonol content between $100 \%$ methanol at $50{ }^{\circ} \mathrm{C}$ and $30{ }^{\circ} \mathrm{C}$ extractions. Also, in methanol extractions, myricetin was the dominant free flavonol rather than myricetin-3-O-glucoside, as in the case of water extractions. This was followed by quercetin-3-O-glucoside and myricetin-3-O-glucoside, whilst kaempferol was the lowest $(p<0.05)$ free flavonol $(\sim 2.8 \mathrm{mg} / 100 \mathrm{~g})$ detected in the methanol extractions. 
403 higher free flavonol content $(\sim 58.5 \mathrm{mg} / 100 \mathrm{~g})$ than at $30^{\circ} \mathrm{C}(\sim 53.6 \mathrm{mg} / 100 \mathrm{~g})$. Myricetin-3-O-

404 glucoside and quercetin-3-O-glucoside were the main free flavonols detected in all extractions, 405 i.e. with different methanol/water ratios and extraction temperatures. Furthermore, in terms of 406 the solvent used, $100 \%$ methanol at $50{ }^{\circ} \mathrm{C}$ and $30{ }^{\circ} \mathrm{C}$ were the most suitable extraction systems/ 407 conditions to obtain the highest concentration of free flavonol ( $71.5 \mathrm{mg} / 100 \mathrm{~g})$ compared to 408 water, methanol/water and acid.

409 Notably, Table 4 demonstrates that the type of extractant influenced the individual free 410 flavonol yield, with myricetin-3-O-glucoside ( 29.0\%) and quercetin-3-O-glucoside $(\sim 25.4 \%)$ 411 being the main free flavonols $(p<0.05)$ detected in water, methanol/water and acetic acid buffer 412 pH 1.5 extracts. Whilst, 100\% methanol contained higher amount $(p<0.05)$ of myricetin 413 ( 25.0\%). Upon acid hydrolysis as shown in Table 4, significantly $(p<0.05)$ higher myricetin $414(\sim 63.6 \%)$ was detected compared to quercetin $(36.4 \%)$. Overall, the total content of free

415 flavonols were 1.1 to 3.0 times higher than their hydrolysed aglycones. Similar to 416 anthocyanidins, these flavonol aglycones were released by acid hydrolysis of the flavonols 417 glycosides that still remaining in cell vacuole after solvent extraction (Figure $3 \mathbf{b}$ ). This was in 418 accordance with the findings by Moussa-Ayoub, El-Samahy, Kroh, \& Rohn (2011) who 419 reported that acid hydrolysis of dried cactus peel for $1 \mathrm{~h}$ at $90{ }^{\circ} \mathrm{C}$ caused the degradation of 420 flavonols to form the respective aglycones.

\subsection{Total free phenolics and antioxidant activities of extracts}

Total free phenolics concentration and antioxidant activity of the extracts were 424 determined using the Folin-Ciocalteu method and DPPH assay, respectively. In the acid 425 extraction using acid buffer $\mathrm{pH} 1.5$ at $50{ }^{\circ} \mathrm{C}$, significantly higher $(p<0.05)$ amount of total free 
426 phenolics ( 3702.2 $\mathrm{mg} \mathrm{GAE} / 100 \mathrm{~g})$ and antioxidant activities ( $60.7 \%$ inhibition) were detected

427 compared to extraction at $30{ }^{\circ} \mathrm{C}$ (Figure 4). It is apparent that the low $\mathrm{pH}$ of the acetic acid

428 buffer and high temperature were capable in extracting other compounds besides free phenolics

429 and anthocyanins which most likely contributed to the high antioxidant activities.

430 According to Figure 4, the increase in the extraction temperature from $30{ }^{\circ} \mathrm{C}$ to $50{ }^{\circ} \mathrm{C}$,

431 led to a concomitant increase in the total phenolic content of water extracts. This resulted in an

432 increase in the antioxidant activity from $\sim 16.4 \%$ to $\sim 39.4 \%$ inhibition during the first $2 \mathrm{~h}$ of

433 extraction. Even though anthocyanins were efficiently extracted at $30{ }^{\circ} \mathrm{C}$ (Table 1), the total

434 free phenolic content of methanol extracts at $50{ }^{\circ} \mathrm{C}$ in Figure 4 was found to be significantly $(p$

$435<0.05)$ higher $(\sim 2032.5 \mathrm{mg} \mathrm{GAE} / 100 \mathrm{~g})$, as did the antioxidant activity ( 39.9\% inhibition).

436 Compared to water, methanol was capable in extracting significantly $(p<0.05)$ higher amounts

437 of compounds including phenolics with higher antioxidant activities, hence most likely the 438 reason for this result.

439 Moreover, the extractions carried out at $50{ }^{\circ} \mathrm{C}$ using $70 \%$ and $50 \%$ methanol/water 440 mixtures showed significantly $(p<0.05)$ higher free phenolic contents, ranging between $441 \sim 3236.5$ to $\sim 3337.7 \mathrm{mg} \mathrm{GAE} / 100 \mathrm{~g}$, with higher antioxidant activity $(\sim 56.0 \%$ to $\sim 57.7 \%$ of 442 inhibition) compared to $30{ }^{\circ} \mathrm{C}$ extracts (Figure 4). However, different methanol/water 443 concentrations (70\% and 50\%) did not show any significant difference on the total phenolics 444 and the antioxidant activity between the different extraction temperatures. As expected, $70 \%$ 445 methanol obtained higher free phenolics yield, with a higher antioxidant activity, than $100 \%$ 446 methanol. This is due to the fact that solvent/water mixtures can dissolve both polar and less 447 polar phenolic compounds, as suggested by Vagiri (2014). Overall, extraction at $50{ }^{\circ} \mathrm{C}$ using 448 methanol/water (70\% and 50\%) and especially acetic acid buffer $\mathrm{pH} 1.5$ resulted in the highest 
449 phenolics content ( $\sim 3236.5$ to $\sim 3702.2 \mathrm{mg} \mathrm{GAE} / 100 \mathrm{~g})$ and antioxidant activity $(\sim 56.0 \%$ to $450 \sim 60.7 \%$ of inhibition) compared to other extraction conditions.

451 The Pearson correlation between the total phenolics content and the free anthocyanin 452 content in the obtained extracts was weak, with $\mathrm{R}^{2}=0.628(p<0.05)$, indicating that besides 453 free anthocyanins, there were other phenolic compounds that also reacted with the Folin reagent. 454 Moreover, a study by Häkkinen et al. (1999) showed that phenolic compounds such as 455 hydroxycinnamic acids ( $p$-coumaric, ferulic and caffeic acids) and flavonols (quercetin, 456 myricetin and kaempferol) were also found in blackcurrant fruit extracts. Moreover, Karseno, 457 Yanto, Setyowati, \& Haryanti (2018) and Everette et al. (2014) reported that the Folin reagent 458 is significantly reactive towards other compounds besides phenols such as proteins, organic 459 acids, vitamins and reducing sugars.

460 Kähkönen and Heinonen (2003) also suggested that anthocyanins and their aglycones 461 are powerful antioxidants and possess high antioxidant activity. Therefore, a strong correlation $462\left(\mathrm{R}^{2}=0.802\right)$ with $p<0.05$ was found between the anthocyanin content and antioxidant activity 463 suggesting that besides anthocyanins other phenolics might have also contributed to this 464 attribute. However, $\sim 20 \%$ of the antioxidant activity could be attributed to other phenolics such 465 as hydroxycinnamic acids and flavonols, and potentially to non-phenolic compounds. This is 466 supported by the significant correlation $(p<0.05)$ between the total phenolics content in the 467 DBS extracts and antioxidant activity $\left(\mathrm{R}^{2}=0.935\right)$.

\subsection{Colour of extracts}

Many studies on anthocyanins from fruits investigate their use as natural colourants (He

$471 \&$ Giusti, 2010). In this study, colour measurement aimed to investigate the effect of the 472 extraction conditions to the colour of the extracts. The changes in colour were reported in terms 
473 of colour values $\left(L^{*}, a^{*}, b^{*}\right)$, Total Colour Difference, chroma and hue angle $\left(\mathrm{h}^{\circ}\right)$ as a

474 comparison between the colour of the extracts and the controls (30 min extraction).

475 Even though $50{ }^{\circ} \mathrm{C}$ of acid extract indicated a high amount of free anthocyanins after 2

$476 \mathrm{~h}$ (Table 1), there was a significant $(p<0.05)$ low of $a^{*}$ (redness) and chroma (colour intensity)

477 values indicating extraction at high temperature resulted in a decrease in redness and colour

478 intensity of extracts (Table 5). On the other hand, $a^{*}$ values $(p<0.05)$ was significantly high in

$47930{ }^{\circ} \mathrm{C}$ water extract which led to high chroma. Meanwhile, extraction using $100 \%$ methanol

480 resulted in a significantly $(p<0.05)$ low of $L^{*}$ and $b^{*}$ values, representing an increase in 481 darkness and blueness, respectively. The combination of these values led to significantly $(p<$ 482 0.05) low hue angle values of $100 \%$ methanol extracts compared to other solvents. Moreover, 483 no correlation was observed between anthocyanins content and chroma and redness. These 484 proved that rather than anthocyanins content, colour properties of the extracts were influenced 485 more by the $\mathrm{pH}$ values of the extraction solvents, as reported by Wrolstad (2004) and Pedro, 486 Granato, \& Rosso (2016). Furthermore, statistical analysis using Two-way ANOVA shows the 487 significant interaction $(p<0.05)$ between solvent and extraction temperature on the $L^{*}, a^{*}, b^{*}$, 488 Total Colour Difference and chroma values.

\section{CONCLUSIONS}

The extraction yields of free phenolic compounds (including free anthocyanins) from

492 dried blackcurrant skins were mainly affected by the choice of solvent and extraction 493 temperature. Generally, higher extraction temperature $\left(50{ }^{\circ} \mathrm{C}\right)$ was more effective than $30{ }^{\circ} \mathrm{C}$.

494 The application of low $\mathrm{pH}$ of acetic acid buffer $(\mathrm{pH} 1.5)$ at $50{ }^{\circ} \mathrm{C}$ efficiently extracted higher 495 amounts of free anthocyanins, free hydroxycinnamic acids, total free phenolic content and 496 antioxidant activity compared to water and solvent extractions. The extracts contained relatively 
high amounts of total free phenolic compounds and exhibited superior antioxidant activity, as

498 well as good colour intensity. Moreover, HPLC profiling results show that anthocyanins, 499 hydroxycinnamic acids and flavonols are dependent on the type of solvent used. In this study,

500 acid hydrolysis method produced bound anthocyanins, anthocyanidins, bound hydroxycinnamic 501 acid ( $p$-coumaric acid) and flavonol aglycones from dried blackcurrant skins residue. The yields 502 of these bound phenolic compounds were mainly lower than that of their free forms. Overall, 503 the yield of total free phenolics and free anthocyanins were strongly correlated with high 504 antioxidant activity. However, colour properties did not correlate with the free anthocyanin 505 contents but depended considerably on solvent type and extraction temperature used. Also, in 506 order to reduce the cost of extraction, liquid-liquid extraction should be conducted to recover 507 and recycle the acetic acid.

\section{ACKNOWLEDGEMENTS}

510 The authors wish to acknowledge the Malaysian Higher Education and Universiti Putra 511 Malaysia (UPM) for the financial support of this research. Also, we would like to acknowledge 512 Purn House Farm (Bleadon, Weston-super-Mare, UK) for kindly supplying us with 513 blackcurrants by-products.

515 CONFLICTS OF INTEREST

516 The authors declared no conflicts of interest.

\section{AUTHOR CONTRIBUTIONS}

519 EMA conducted the research, interpreted the results, and drafted the manuscript. DC and AC 520 conceptualized, designed the study and reviewed- finalized the manuscript. 


\section{References}

523 Amr, A., \& Al-Tamimi, E. (2007). Stability of the crude extracts of Ranunculus asiaticus anthocyanins and their use as food colourants. International Journal of Food Science and Technology, 42(8), 985-991.

Acosta-Estrada, B. A., Gutiérrez-Uribe, J. A., \& Serna-Saldívar, S. O. (2014). Bound phenolics in foods, a review. Food Chemistry, 152, 46-55.

Andersen, O. M., \& Markham, K. R. (2005). Flavonoids: chemistry, biochemistry and applications. CRC press.

530 Arvanitoyannis, I. S. (2010). Waste management for the food industries. Academic Press.

531 Basegmez, H. I. O., Povilaitis, D., Kitryte,, V., Kraujalienè, V., Šulniūtè, V., Alasalvar, C., \& 532 Venskutonis, P. R. (2017). Biorefining of blackcurrant pomace into high value functional ingredients using supercritical $\mathrm{CO} 2$, pressurized liquid and enzyme assisted extractions. The Journal of Supercritical Fluids, 124, 10-19.

535 Battino, M., Beekwilder, J., Denoyes-Rothan, B., Laimer, M., McDougall, G. J., \& Mezzetti, B. (2009). Bioactive compounds in berries relevant to human health. Nutrition Reviews, 67 , $\mathrm{S} 145-\mathrm{S} 150$.

Blois, M. S. (1958). Antioxidant determinations by the use of a stable free radical. Nature

540 Boeing, J. S., Barizão, É. O., e Silva, B. C., Montanher, P. F., de Cinque Almeida, V., \& 541 Visentainer, J. V. (2014). Evaluation of solvent effect on the extraction of phenolic 542 compounds and antioxidant capacities from the berries: Application of principal 543 component analysis. Chemistry Central Journal, 8(1), 1-9. 
544 Borges, G., Degeneve, A., Mullen, W., \& Crozier, A. (2009). Identification of flavonoid and 545 phenolic antioxidants in black currants, blueberries, raspberries, red currants, and 546 cranberries. Journal of Agricultural and Food Chemistry, 58(7), 3901-3909.

547 Brennan, R., \& Graham, J. (2009). Improving fruit quality in Rubus and Ribes through $548 \quad$ breeding. Functional Plant Science and Biotechnology, 3, 22-29.

549 Durazzo, A. (2018). Extractable and Non-extractable Polyphenols: an Overview. In Non$550 \quad$ extractable Polyphenols and Carotenoids (pp. 37-45).

551 Everette, J. D., Bryant, Q. M., Green, A. M., Abbey, Y. A., Wangila, G. W., \& Walker, R. B. 552 553 (2010). Thorough study of reactivity of various compound classes toward the FolinCiocalteu reagent. Journal of Agricultural and Food Chemistry, 58(14), 8139-8144.

554 Gulsunoglu, Z., Karbancioglu-Guler, F., Raes, K., \& Kilic-Akyilmaz, M. (2019). Soluble and 555 556 insoluble-bound phenolics and antioxidant activity of various industrial plant wastes.

Haminiuk, C. W. I., Plata-Oviedo, M. S. V., de Mattos, G., Carpes, S. T., \& Branco, I. G. (2014).

558 Extraction and quantification of phenolic acids and flavonols from Eugenia pyriformis 559 using different solvents. Journal of Food Science and Technology, 51(10), 2862-2866.

560 Harbourne, N., Marete, E., Jacquier, J. C., \& O'Riordan, D. (2013). Conventional extraction 561 techniques for phytochemicals. Handbook of Plant Food Phytochemicals: Sources,

563 Häkkinen, S., Heinonen, M., Kärenlampi, S., Mykkänen, H., Ruuskanen, J., \& Törrönen, R. 564 (1999). Screening of selected flavonoids and phenolic acids in 19 berries. Food Research International, 32(5), 345-353.

566 He, J., \& Giusti, M. M. (2010). Anthocyanins: natural colourants with health-promoting 567 properties. Annual Review of Food Science and Technology, 1, 163-187. 
568 Hertog, M. G., Hollman, P. C., \& Venema, D. P. (1992). Optimization of a quantitative HPLC 569 determination of potentially anticarcinogenic flavonoids in vegetables and $570 \quad$ fruits. Journal of Agricultural and Food Chemistry, 40(9), 1591-1598.

IBA

(International

Blackcurrant

Association)

(2018). http://www.internationalblackcurrantassociation.com. Accessed 13 August 2018.

Kähkönen, M. P., Hopia, A. I., \& Heinonen, M. (2001). Berry phenolics and their antioxidant activity. Journal of Agricultural and Food Chemistry, 49(8), 4076-4082.

Kähkönen, M. P., \& Heinonen, M. (2003). Antioxidant activity of anthocyanins and their aglycons. Journal of Agricultural and Food Chemistry, 51(3), 628-633.

Kapasakalidis, P. G., Rastall, R. A., \& Gordon, M. H. (2006). Extraction of polyphenols from processed black currant residues. Journal of Agricultural and Food Chemistry, 54(11), 4016-4021.

Karseno, E., Yanto, T., Setyowati, R., \& Haryanti, P. (2018). Effect of pH and temperature on

Laaksonen, O. A., Mäkilä, L., Sandell, M. A., Salminen, J. P., Liu, P., Kallio, H. P., \& Yang, B. 584 (2014). Chemical-sensory characteristics and consumer responses of blackcurrant juices 585 browning intensity of coconut sugar and its antioxidant activity. Food Research, 2(1), $32-38$.

587 Lapornik, B., Prošek, M., \& Wondra, A. G. (2005). Comparison of extracts prepared from plant 588 by-products using different solvents and extraction time. Journal of Food Engineering, 71(2), 214-222.

590 Lee, J., Durst, R. W., \& Wrolstad, R. E. (2005). Determination of total monomeric anthocyanin 591 pigment content of fruit juices, beverages, natural colorants, and wines by the $\mathrm{pH}$ 

1278.

594 Mäkilä, L., Laaksonen, O., Alanne, A. L., Kortesniemi, M., Kallio, H., \& Yang, B. (2016). Stability of Hydroxycinnamic Acid Derivatives, Flavonol Glycosides, and Anthocyanins in Black Currant Juice. Journal of Agricultural and Food Chemistry, 64(22), 4584-4598.

Moussa-Ayoub, T. E., El-Samahy, S. K., Kroh, L. W., \& Rohn, S. (2011). Identification and 598 quantification of flavonol aglycons in cactus pear (Opuntia ficus indica) fruit using a commercial pectinase and cellulase preparation. Food Chemistry, 124(3), 1177-1184.

600 Oancea, S., Stoia, M., \& Coman, D. (2012). Effects of extraction conditions on bioactive 601 anthocyanin content of Vaccinium corymbosum in the perspective of food applications. Procedia Engineering, 42, 489-495.

603

604

605

606

Padayachee, A., Netzel, G., Netzel, M., Day, L., Mikkelsen, D., \& Gidley, M. J. (2013). Lack of release of bound anthocyanins and phenolic acids from carrot plant cell walls and model composites during simulated gastric and small intestinal digestion. Food \& Function, 4(6), 906-916.

Panche, A. N., Diwan, A. D., \& Chandra, S. R. (2016). Flavonoids: an overview. Journal of Nutritional Science, 5.

Pedro, A. C., Granato, D., \& Rosso, N. D. (2016). Extraction of anthocyanins and polyphenols from black rice (Oryza sativa L.) by modeling and assessing their reversibility and stability. Food Chemistry, 191, 12-20.

612 Rodriguez-Saona, L. E., \& Wrolstad, R. E. (2001). Extraction, isolation, and purification of anthocyanins. Current Protocols in Food Analytical Chemistry.

614 Sandell, M., Laaksonen, O., Jarvinen, R., Rostiala, N., Pohjanheimo, T., Tiitinen, K., \& Kallio, 615 H. (2009). Orosensory profiles and chemical composition of black currant (Ribes 

nigrum) juice and fractions of press residue. Journal of Agricultural and Food Chemistry, 57(9), 3718-3728.

618 Saura-Calixto, F. (2012). Concept and health-related properties of nonextractable polyphenols: 619 the missing dietary polyphenols. Journal of Agricultural and Food Chemistry, 60(45), 620 $11195-11200$.

Sójka, M., \& Król, B. (2009). Composition of industrial seedless black currant pomace. European Food Research and Technology, 228(4), 597-605.

Spigno, G., Tramelli, L., \& De Faveri, D. M. (2007). Effects of extraction time, temperature and solvent on concentration and antioxidant activity of grape marc phenolics. Journal of Food Engineering, 81(1), 200-208.

Szajdek, A., \& Borowska, E. J. (2008). Bioactive compounds and health-promoting properties of berry fruits: a review. Plant Foods for Human Nutrition, 63(4), 147-156.

Vagiri, M. R. (2014). Phenolic compounds and ascorbic acid in black currant (Ribes nigrum L.).

Varming, C., Petersen, M. A., \& Poll, L. (2004). Comparison of isolation methods for the determination of important aroma compounds in black currant (Ribes nigrum L.) juice, using nasal impact frequency profiling. Journal of Agricultural and Food Chemistry, 52(6), 1647-1652.

Waterman, P. G., and Mole, S. (1994). Analysis of phenolic plant metabolites. Blackwell Scientific.

Wrolstad, R. E. (2004). Anthocyanin pigments-Bioactivity and colouring properties. Journal 638 of Food Science, 69(5), C419-C425.

Wrolstad, R. E., \& Smith, D. E. (2010). Colour analysis. In Food analysis (pp. 573-586). Springer US. 
639 Zhang, H., \& Tsao, R. (2016). Dietary polyphenols, oxidative stress and antioxidant and anti640 inflammatory effects. Current Opinion in Food Science, 8, 33-42. 